\title{
EDUCACIÓN FORMAL: ¿ROMPIENDO O PERPETUANDO MITOS?
}

\author{
Vivian Carvajal Jiménez ${ }^{1}$
}

\section{Resumen}

El artículo expone las condiciones históricas y sociales que han desencadenado en que la Educación Formal, lejos de romper mitos y estereotipos en relación con el tratamiento de género y la posición femenina, perpetúe estas situaciones y legitime ciertas prácticas a través del uso de textos, materiales didácticos y prácticas curiculares.

\section{Abstract}

Explanation of the historical and social conditions that have led formal education to - far from dispelling the myths and stereotypes on the treatment of gender issues and female position- perpetuate these situations and legitimate certain practices through the use of biased textbooks, teaching materials and curriculum practices.

\section{Palabras claves}

Perpetuación de mitos, tratamiento de género, textos educativos, sociedad.

\section{Introducción}

Dor todas partes se pregona el consabido hecho de que cada individuo reúne características, antecedentes y habilidades distintas y que, por lo tanto, es un ser único que requiere de diferentes maneras para satisfacer sus muy personales necesidades. Estas necesidades no sólo se inscriben en la individualidad, sino que tienen estrechas y complicadas relaciones con el medio en que se desenvolvió una persona, con sus antecedentes históricos o familiares, con la época y el país o región donde le tocó vivir, además de un sinfín de determinantes como la clase social, las convicciones familiares, la etnia, el poder económico y la cultura.

\footnotetext{
I Académica en la División de Educación Rural, CIDE, Universidad Nacional. Profesora de Español en Enseñanza Media en el Liceo Hernán Zamora. Filóloga Hispánica, Licenciada en Docencia y Magíster en Psicopedagogía. viviancj@costarricense.cr
} 
En el plano educativo, resulta más que importante tomar en consideración estas variables, pues toda(o) docente y administradora y administrador educativa(o) debe ser consciente de que trabaja con personas capaces, diferentes entre sí y pertenecientes a diversas realidades.

Por otro lado, las nuevas modalidades educativas, los actuales contenidos curriculares, las tendencias hacia la inclusión y las nuevas maneras de comprender la administración educativa, contribuyen a que se tenga una visión más amplia del quehacer docente y gerencial por parte de estudiantes, docentes y la sociedad en general.

No obstante, a la hora de desarrollar el proyecto de modernización y optimización educativa, siguen quedando de lado algunos aspectos vitales; en especial, cuando se impone por la fuerza toda una serie de normas que más que favorecer la educación y el aprendizaje real, interfieren con la adquisición de conocimiento y el disfrute genuinos. En palabras de Bernardini (1985, p. 31): "Para mejorar la educación costarricense hay que revisar muy a fondo la formación de los educadores... Habría entonces que revisar la mentalidad, los criterios formativos que están detrás de los títulos".

Si se quiere ofrecer un panorama general en cuanto a los puntos que necesitan mejoras en la enseñanza y la administración educativa, primero deben revisarse las estrategias metodológicas empleadas por las y los docentes, los postulados que aparecen en los programas que el Ministerio de Educación Pública da como rubros a seguir, el material didáctico utilizado en las aulas, los lineamientos y formas de trabajo que siguen las y los docentes y la instrucción misma que las y los estudiantes de docencia reciben en las aulas universitarias.

Entre muchos otros cambios y temas de apremiante atención, destaca, desde hace años, la forma en que la Educación visualiza las diferencias de género, el tratamiento inclusivo que se hace con respecto a lo femenino y la toma de posiciones tradicionales en cuanto al papel de mujeres y hombres en la sociedad. ¿Por qué razón ligar la socialización de género a la instrucción formal? Marx (1970, p. 115) responde a la cuestión cuando señala que “...las clases dominantes desarrollan formas ideológicas que legitiman su dominación: la clase que tiene los medios de producción material a su disposición, tiene al mismo tiempo el control sobre la producción cultural", y por ende, sobre los mecanismos que llevan estas ideologías a las masas; la más elemental, por supuesto, la escolarización.

Se ha mencionado que los grupos dominantes, llámense líderes religiosos, portentos políticos o dueños de la economía, son los que, de una u otra manera, proponen las ideologías, prácticas y restricciones que una sociedad acoge. Por siglos, estos grupos se han encargado de relegar a las minorías (o 
por lo menos, a los grupos que han propuesto como tales) y a los grupos que tradicionalmente han sido excluidos de la esfera de la toma de decisiones. Al respecto, Bernstein (1975) indica que “...la forma en que una sociedad clasifica, distribuye, transmite y evalúa el conocimiento educativo que considera como público, refleja a la vez la distribución del poder y los principios de control de la sociedad". Siendo así la situación, cabe preguntarse el papel que desempeñan los programas educativos planteados por el Ministerio de Educación Pública, los materiales educativos que se distribuyen en las tiendas y los materiales didácticos que se les recomiendan a nuestras(os) jóvenes.

Hace poco más de una década, un grupo de educadoras(es), preocupadas(os) por los estereotipos y conductas que los libros de texto transmitían explícitamente, logró retirar de entre los textos “oficiales” el conocido Paco y Lola, con que tantas generaciones aprendieron a leer decodificando símbolos, conductas y papeles asignados a mujeres y hombres. Pero, ¿fue este el aporte definitivo que hizo que nuestro sistema educativo rompiera mitos? o ¿fue apenas una reacción que sirvió para ocultar los muchos otros discursos que, ahora sí más solapadamente, siguen perpetuando prejuicios misóginos y dañinas conductas machistas?

Es sumamente difícil transformar prácticas sustentadas en ideologías que la institucionalización ha consolidado, por lo que no extraña que el proceso sea lento y que todavía hoy, cuando Costa Rica se enorgullece por sobresalir en América como una de las pocas naciones en que la alfabetización cubre por igual a hombres y mujeres, se descubran líneas de desigualdad de género que la Educación Formal alimenta.

No obstante, como en todas las épocas, es imprescindible trabajar para poner en evidencia los baches que fomenten cualquier tipo de discriminación, sobre todo en el ámbito escolar. Un breve recorrido por prácticas, textos y posiciones ligadas a la Educación Formal, ayudará a descubrir en qué medida se rompen los mitos de género en las aulas costarricenses.

¿De dónde provienen los gérmenes que fomentan distinciones entre mujeres y hombres? ¿A qué se debe que se hable de conductas distintas para cada género? ¿Por qué razón las instancias educativas han establecido formas de tratamiento que difieren con respecto a uno y otro sexo (durante años se programó la clase de Artes Industriales solamente para los varones y la clase de Educación para el Hogar para las jovencitas; todavía hoy, las clases de Educación Física se imparten a mujeres y hombres por separado).

La socialización a la que todas(os) nos vemos sometidas(os) hace que las conductas (y muchas veces las inclinaciones y el desarrollo físico) de mujeres y hombres difiera en múltiples sentidos; pues lo que se ha inculcado como femenino o masculino determina infinitas áreas de la vida: la forma de vestir, los 
colores a escoger, el comportamiento público, el desarrollo motor (a raíz de ciertos juegos o posturas), las profesiones a elegir, la manera de hablar, el léxico que se emplee y la manera de intervenir en un asunto, entre muchos otros aspectos.

El papel que la Educación ha jugado con respecto a esta diferenciación, y la manera en que, actualmente, los sexos son visualizados por dicha instancia, es lo que ocupa este apartado.

\section{La Educación a través de un manto religioso}

Por mucho tiempo, la Educación Formal, reconocida como marca de estatus, estuvo en manos de la Iglesia, no sólo en Occidente, sino en todas partes del mundo (monjes hindúes, budistas, judíos y musulmanes, eran considerados "maestros" y sabios y los contrataban las familias más acaudaladas para impartirles instrucción a sus hijos). Con esta acotación en mente y teniendo presente el papel que se le atribuye a la mujer en la mayoría de credos y organizaciones religiosas, no sorprende que por siglos se haya educado a la gente para que el hombre tuviera una posición de superioridad en relación con la mujer.

Un clarísimo modelo se establece en los libros sagrados que han servido como pilar de las enseñanzas religiosas divulgadas en el mundo. La Biblia, el Corán, el Talmud, las tradiciones míticas de distintas civilizaciones, y muchas otras obras, colocan a la mujer en una posición desventajosa con respecto al varón. La tradición judeocristiana, por ejemplo, le señala a la mujer que “...tu deseo vehemente será por tu marido, y él te dominará” (Génesis 3:16). En la misma línea, el Nuevo Testamento y el apóstol Pablo sentencian al género femenino al decir: "Que la mujer aprenda en silencio, con plena sumisión" (1 Timoteo 2:11). Con respecto al Corán, no se puede obviar el "derecho" que se le otorga al esposo, al anunciarle que “...es bondadoso golpear a su mujer”.

De forma parecida, los mitos griegos dibujan el perfil de mujer y su función social: Casandra, quien es catalogada de bruja y mentirosa, debe guardar prudencia para no ser atacada, simplemente por ser profeta y declarar la verdad. Penélope, la fiel esposa de Odiseo, aguarda pacientemente la vuelta del marido infiel que ha desaparecido por largos años. Medea, la traicionada, quien osa vengarse de su marido, es la antítesis de lo maternal. Alcestes, mujer ángel, quien entrega gustosa la vida para salvar a su esposo; y Pandora, que como Eva, es acusada de traerle todas las desgracias a la humanidad.

Así, la Iglesia, primera institución que administró la docencia formal, no hizo más que perpetuar mitos y actitudes sexistas, en especial, en lo que se refiere al conocimiento y a la mujer intelectual. Yadira Calvo (1984, p. 35) 
retomó el asunto al señalar que “...la curiosidad se sanciona en las mujeres precisamente porque representa una iniciación al conocimiento, y por lo tanto, un atributo masculino, según el prejuicio de que todo lo bueno es viril. Lo que en el varón es virtud en la mujer es vicio...". Al respecto, Tannen (1993) desarrolla toda una tesis alrededor de lo que es catalogado como "chisme" y las posturas que suelen adoptarse cuando el conocimiento acerca de algo proviene de una mujer o de un hombre. Para esta investigadora, lo que tradicionalmente se conoce como "chisme" es una concepción social referente a la manera en que las mujeres suelen establecer conexiones e incluir a otras(os) en su círculo. De nuevo, Calvo (1984, p. 120) menciona que “...en la lucha por la liberación de las mujeres, uno de los factores más penosos e importantes consistió en infringir las prohibiciones que se les imponían sobre el lenguaje. La obligación de callarse lleva implícita la de tolerar, cosa que prevé de manera clara el refrán: el que calla concede". Este es apenas uno de los muchos ejemplos que podrían citarse para ilustrar el celaje negativo que recubre a las mujeres y la visión distorsionada que suele manipularse cuando una fémina es poseedora del conocimiento.

Sin duda, uno de los emisores que ha divulgado e institucionalizado prejuicios relativos a la superioridad de un sexo sobre otro es la Educación Formal, ligada a diversas instancias ideológicas de índole religiosa. Sin embargo, otras fuerzas también influyentes en la Educación, aportaron su dosis de presión para que el patriarcado fuera justificable.

\section{La Fisiología y la Psicología: justificantes de la Educación Formal}

Muchas aproximaciones fisiológicas suponen diferencias entre sexos; algunas tendientes a lo genético, lo hormonal o lo anatómico. Entre ellas, sobresalen las observaciones de ciertas especies en que prima una organización jerárquica con un macho fuerte, protector y dominante; o bien, el análisis de ciertos animales en que el cuido de las crías recae sobre la hembra.

De igual manera, para establecer distinciones entre mujeres y hombres, se ha tomado como base la capacidad muscular y el desarrollo de ciertas potencialidades asociadas con la fuerza física; aunque bien puede ser que estén determinadas por el ambiente y la ejercitación, y no precisamente por una condición anatómica innata.

Por su parte, Sigmund Freud (1967) desarrolló una completa teoría psicológica que ha sido interpretada como justificación del dominio masculino. Hay quienes deducen del análisis del complejo de castración, experimentado por la mujer, no sólo la posición inferior de esta, sino la presencia de un menor 
sentido de la justicia y la propensión a dejarse llevar por las emociones más que por lo racional: "Lo masculino comprende el sujeto, la actividad y la posesión del pene. Lo femenino integra el objeto y la pasividad" (p. 1197). De hecho, uno de los seguidores del padre de la Psicología, Erick Fromm (1972, p. 121), indicó que “...Freud, influido por su prejuicio a favor de la autoridad paterna y de la superioridad masculina, interpretó material clínico en forma unilateral...”.

De esta manera, la Educación Formal se alimentó de patrones e hipótesis que, al igual que las instituciones religiosas, colocaban a la mujer en una posición de desventaja social, pero que por su reconocimiento internacional, resultaban confiables y convenientes.

\section{La división del trabajo}

Un hecho que definitivamente implicó que la Educación Formal acuñara ciertas prácticas con respecto a la posición de lo femenino y lo masculino fue la incursión de la mujer en el mercado laboral y la división de funciones establecida para tal efecto, pues las posibilidades de desarrollo e influencia social de un individuo dependen, en buena medida, del tipo de trabajo que realice.

Ocultar conocimientos es, desde la antigüedad, una manera en que los grupos dominantes se aseguran de conservar el poder y control sobre los demás; dado que tener acceso al conocimiento implica también una suerte de liberación y una posibilidad de apropiación y desarrollo económico que, a la larga, otorga mayor autonomía en la toma de decisiones.

Con la revolución tecnológica e industrial y los cambios que las guerras mundiales trajeron, de pronto, la mujer que había sido recluida en casa y destinada a la crianza de las(os) hijas(os) (a lo sumo, se consideraba buena para el oficio de maestra) tenía que salir a trabajar y desempeñarse como obrera. Para este nuevo papel, debía entrenarla la Educación Formal, pues se requería de las féminas algunas destrezas que antaño no importaban. No obstante, ya en posguerra, nuevas fuerzas sociales se encargaron de contener las aspiraciones laborales de las mujeres, y se continuó sacralizando la función de mujer-madre: comenzó a oponerse esta obligación a la actividad laboral, por considerar antagónico el desempeño económico con el de madre.

Muchos autores, entre los que destaca Engels (1975), consideran que las primeras distinciones sociales entre géneros se dieron por razones relacionadas con la maternidad, en vista de que esta implicaba una época en que la mujer caía en cierto "sedentarismo"; situación que no tardó en ser aprovechada por los varones para recargar en sus parejas, ya de forma definitiva, todas las funciones concernientes a la crianza y educación de las(os) hijas(os) y, de paso, las labores domésticas. 
Por su parte, Durán (1983, p. 31) alude a la utilización económica de la maternidad y sus implicaciones: "A partir de una perspectiva conservadora, esta condición biológica ha sido constantemente utilizada para negar a la mujer cualquier otro papel social y cualquier otra capacidad, confinándola casi exclusivamente a su papel de productora familiar". Este mismo autor considera que las actividades manual, intelectual y afectiva del ama de casa (oficio que se ha destinado a la mujer), por su carácter repetitivo y rutinario, van a repercutir en sus posibilidades de desarrollo del pensamiento abstracto; de la misma manera en que ocurre con los varones que son "encerrados" y condenados a la ejecución de los mismos oficios en forma mecánica.

Por lo tanto, la división de tareas por géneros y el papel de la Escuela como transmisora de roles e instructora y modeladora de destrezas tienen mucha relación con la perpetuación de mitos en torno al papel productivo del hombre y la mujer.

\section{Los supuestos educativos y algunas evidencias}

Refiriéndose específicamente a los modelos transmitidos por las instituciones que conforman el sistema educativo, es necesario echarle un vistazo a las prácticas desarrolladas en las aulas, a los textos y al material didáctico que se emplea en los salones de clase, así como al lenguaje y las connotaciones de ciertas actitudes que se presencian en el ambiente escolar.

González (2000) señala como el defensor más sobresaliente del sexismo a la aceptación de patrones conductuales, que dejan de ser vistos como tales y pasan a ser percibidos como lógicos, naturales, permanentes e inevitables. En esta línea, González sitúa toda una serie de prácticas y actividades ligadas con la escolaridad; entre ellas, la proporción de modelos femeninos y masculinos ofrecidos en los libros de texto, los trabajos que, en esos libros, aparecen desempeñando mujeres y hombres, los juegos asignados por sexo y la importancia social que se le da a personajes históricos masculinos.

Aunque más de la mitad de la población mundial está compuesta por mujeres, de acuerdo con González (2000), en los libros de texto que se utilizan regularmente en las aulas, esa proporción no se acerca a la realidad; pues apenas un $28 \%$ de los modelos presentados son personajes femeninos. Asimismo, la autora destaca la omisión generalizada de lo femenino como otro de los grandes protagonistas de la Educación Formal (al citar ejemplos de oraciones, donde suele emplearse un nombre masculino o el pronombre personal él).

Por su parte, Moreno (2003, p. 4) menciona que “...los libros de texto no solo enseñan la materia escolar, ni es el dominio de ese saber en concreto lo 
único que cultivan, sino todo un código de símbolos sociales que comportan una ideología sexista, no explícita, pero increíblemente más eficaz que si estuviera expresada”. ¿Por qué este autor hace tal aseveración? En su artículo, Moreno expresa la posición de los modelos femeninos que suelen encontrarse en los libros escolares: personajes marginados, escasa aparición de mujeres en actividades laborales y prolongación del papel maternal de la mujer (madres, enfermeras, niñeras y maestras en actitud maternal): "A veces aparece un personaje femenino que se limita a esperar, soñando el retorno del héroe. La historia importante es la historia de los hombres, las mujeres solo son un apéndice" (p. 2).

En un estudio efectuado por la UNIFEM (citado por Barrios y Gutiérrez, 1990), se destaca que la presencia femenina es muy inferior a la masculina en actos y textos escolares. De acuerdo con el estudio, la aparición de las mujeres es de menos de un tercio de lo que lo hacen los hombres.

La presencia femenina es alta solo cuando se trata de rasgos tradicionalmente identificados como femeninos: afectividad, pasividad, miedo, vacilación, limpieza, docilidad y procreación. Por el contrario, es baja cuando se trata de rasgos del carácter que indican fortaleza, agresividad, valentía, liderazgo, independencia, firmeza o dinamismo. Pero posiblemente el asunto más grave se refiere al hecho de que, tratándose de libros de estudio, la presencia femenina sea también muy baja respecto de personajes que reflejan inteligencia (Barrios y Gutiérrez, 1990, p. 2).

El asunto es relevante cuando se analizan detenidamente los rasgos y las particularidades que son típicos en los personajes femeninos que aparecen en los textos. Mora, Muñoz y Villareal (2001) recogen datos relacionados con la percepción de la imagen corporal que un grupo de adolescentes tenía sobre sí mismos. Es curioso notar que el estudio remite a la imagen de mujer bella en relación con los modelos que le son ofrecidos por la publicidad, la escuela y el entorno social.

Al respecto, Palomar (2003) destaca el papel del currículo en la prolongación de mitos genéricos; al igual que Moreno, reflexiona en los modelos que se transmiten mediante imágenes y lecturas. La escritora señala, además, las actividades extracurriculares como separadoras y diferenciadoras de roles: las niñas van a clases de ballet; los niños están en el equipo de "papi"; los niños hacen ejercicio considerado como "fuerte", las niñas bailan o hacen aeróbicos. Igualmente, Palomar se detiene para hacer una observación relativa al uso del espacio en el tiempo libre: son los varones quienes, por lo general, se apropian 
de las amplias zonas verdes, mientras que las niñas se quedan en los pasillos. Sobre esta situación, Tannen (1993) menciona algunos estudios y observaciones en que, efectivamente, se corrobora que desde niños, los juegos de varones se caracterizan por un uso amplio y nada tímido del espacio, en tanto que las mujeres son acostumbradas a jugar, socializar y desarrollar su estilo comunicativo en la intimidad, en espacios pequeños y, por consiguiente, con escaso movimiento.

Por otra parte, en cuanto a la voz femenina, varios estudios insisten en señalar que la presencia masculina es siempre más notoria, pues las intervenciones orales de los varones son más amplias y más frecuentes. Sobre este asunto, Tannen (1993) desarrolla una tesis alrededor de los estilos comunicativos, aduciendo que las mujeres suelen desenvolverse mucho mejor en el habla privada y que, además, producto de la socialización, no gustan de "lucir sus conocimientos u opiniones" de forma directa, aspecto que sí ha sido estimulado en los varones: "como las mujeres buscan primordialmente crear rapport, tienden a dejar de lado sus experiencias más que a mostrarlas. Como los hombres valoran la posición de centro y la sensación de saber más que el otro, buscan las oportunidades de mostrar y dan a conocer información fáctica" (p. 128).

Al respecto, Lozano (1998) asegura que “...para las mujeres el principal objetivo en una conversación es la relación que se establece entre ambas interlocutoras a través del lenguaje, por lo tanto, todos los esfuerzos comunicativos irán dirigidos a comprender a la otra persona, captar su sicología y el significado de lo que quiere decir..."; igualmente, ambas autoras rescatan el hecho de que los varones "se sienten obligados" a emitir alguna opinión en situaciones públicas, pues no pueden pasar como desposeedores de conocimiento. Si esto es así, y en realidad hay menos participación de la voz femenina en el habla pública, bien podría deberse a una diferencia de estilo conversacional.

Otro aspecto que autoras como Palomar (2003) y Calvo (1990) señalan en cuanto a los patrones que la Educación promueve a través de los textos didácticos que se emplean en escuelas y colegios, y mediante el currículo mismo, es el uso de genéricos en el lenguaje; esto cuando las voces llamadas neutras se emplean para incluir a la parte femenina. Según estas investigadoras, tal hecho invisibiliza a la mujer y da por sentado que lo femenino no necesita ser mencionado de manera particular, pues no porta la importancia que sí posee lo masculino.

Para realizar el análisis de algunas evidencias que muestren si la Educación Formal costarricense está perpetuando o no mitos en torno a la igualdad o desigualdad de géneros, se hizo una revisión de varias vivencias escolares y materiales educativos, entre ellos: 
a) Cuentos y narraciones que forman parte de las lecturas obligatorias según los programas educativos del Ministerio de Educación Pública ("La Ajorca de Oro" en sétimo año; "El Hijo" en octavo año) y los análisis respectivos que aparecen como guías en los tex tos complementarios (Santillana y Textos de Lectura y Comentarios).

b) Producciones y creaciones realizadas por 180 alumnas(os) de sétimo año (del Liceo Hernán Zamora) y por 30 estudiantes de segundo año de universidad de la carrera de Educación Rural de la Universidad Nacional (UNA).

c) Libros de texto de distintas materias y diferentes años (Ciencias, Matemática, Estudios Sociales, Lectoescritura).

d) Grabaciones de discusiones sostenidas en la clase de Español en grupos de noveno año.

e) Recopilación de impresiones de estudiantes de secundaria con respecto a los papeles de mujeres y hombres (10 de sétimo y 35 de noveno año).

f) Entrevistas a educadoras(es) de preescolar, primaria y secundaria (6 entrevistas, 2 por nivel).

g) Conversaciones informales sostenidas (6 con docentes de Educación Media de distintas materias).

Entre las limitaciones metodológicas que obstaculizaron de alguna manera la búsqueda de información, puede destacarse la resistencia de las y los docentes a expresar su opinión con respecto a temas de género, así como la desconfianza y oposición a que se asista a sus clases para observar la dinámica desarrollada por el grupo.

También, en el momento de escuchar las grabaciones en que varios estudiantes participaban de una plenaria o debate, era difícil percibir comentarios y actitudes por separado, sobre todo por el ruido y las múltiples voces que se dieron durante la dinámica.

\section{Análisis}

\section{Desde las canciones y los juegos en educación preescolar}

"Iba un pollito para el kínder, con sus calzones muy remendados, iba cantando: ique viva el kínder, que viva la maestra y que viva yo! Cuando de pronto apareció un pato, que al ver al pollo soltó la risa... ¿De qué te ríes le dijo el pollo? De tus calzones muy remendados, pues mis calzones, son muy bonitos porque me los hizo mi mamá". 
“Los pollitos dicen pio, pío, pío, cuando tienen hambre, cuando tienen frío;

la gallina busca el maíz y el trigo, les da la comida y les presta abrigo..."

Estos fragmentos de canciones infantiles, enseñadas y entonadas en la mayoría de instituciones de educación preescolar de nuestro país, reflejan, como muchas otras, los patrones típicos con que se identifica a la mujer: madre, protectora y maestra. Asimismo, los juegos de palmadas y las rondas, que por cierto son mucho más frecuentes entre las niñas, involucran en gran cantidad de sus tonadas, una imagen de lo femenino y lo masculino fuertemente ligada a los estereotipos más tradicionales:

"Arroz con leche me quiero casar, con una señorita de la capital, que sepa coser, que sepa limpiar...

Ayer fui a tu casa, tu hermano me besó, le dije viejo tonto, tu hermano se enojó.

Mi hermana tuvo un baby, la loca lo mató..."

Como queda claro, se sigue privilegiando la función doméstica y procreadora de la mujer y el papel de conquistador del varón.

Además, al revisar materiales como calcomanías, cromos, dibujos, libros y otros implementos usados en las aulas preescolares, se destacan figuras de varones con herramientas, mecánicos y doctores; en dicotomía con mujeres vestidas de ángel (madre), trabajando como maestras o enfermeras. Sin embargo, se comienza a observar que ya aparecen imágenes de mujeres piloteando un avión o de padres jugando con sus hijas(os), que, aunque son siempre una minoría en comparación con las típicas figuras, representan un progreso en las concepciones.

\section{En los métodos iniciales de lectura y escritura}

Gran cantidad de libros de texto empleados como promotores de la lectura y escritura con niñas y niños de primer grado, repiten los modelos típicos para los personajes femeninos y masculinos.

Un ejemplo de ello se observa en el libro de lectura inicial de la serie Tobogán, donde pocas son las figuras femeninas que se cuentan entre las ilustraciones; llama la atención que en dos de las ocasiones en que se recurre a la imagen de mujer, la visión predominante es maternal: la maestra cariñosa y la madre protectora. Incluso, desde la portada del libro existe una manipulación inconsciente de las figuras genéricas: un muchachito leyendo (hombre como 
poseedor del conocimiento) y una niña jugando (tarea ajena a la construcción de aprendizajes).

Otra de las imágenes que se usan en el texto remite a la tradicional ama de casa: la mujer que se encarga de hacer las compras y los oficios (peinada con rulos y la bolsa de las compras). Esta imagen, tras el estereotipo de mujer=servicio doméstico, muestra a una mujer de poca inteligencia que, ni siquiera ayudada por las explicaciones del vendedor, que por supuesto es hombre, puede entender cómo se pesa el queso o con qué medida se vende la leche.

Asimismo, otro ejemplo es uno de los cuentos empleados en las clases de apertura del curso Didáctica de la Lectura y Escritura, impartido a estudiantes de Docencia de la Universidad Nacional. El cuento, "El Rey que deseaba escribir un cuento", que cumple a cabalidad con la motivación hacia la tarea de la escritura creativa, presenta a un rey (varón) que es el poseedor del conocimiento y que, por lo tanto, es quien debe escribir las historias de su pueblo, aunque en alguna parte de la narración se dan indicios de que la prudencia está en su esposa e hija, y no en él precisamente.

También, entre los materiales que acostumbran emplearse como material de apoyo para iniciar el proceso de lectoescritura en las escuelas, se destacan libros de prácticas, ejercicios y apresto, que continúan perpetuando una imagen de lo femenino encajonada en trillados y antiguos estereotipos. Como ejemplo, puede mencionarse Mis primeros pasos en la Lectura y Escritura, un texto que refleja en varias de sus ilustraciones a personajes femeninos que lucen coquetas y delicadas, en oposición a figuras masculinas que están desempeñando algún trabajo.

\section{En los modelos femeninos y masculinos que aparecen en distintos textos escolares y colegiales}

Al revisar las imágenes reportadas por otros libros de texto de diversas materias, de nuevo se puede encontrar una preponderancia de modelos masculinos, en especial, referidas al conocimiento, la investigación y el ejercicio de ciertas profesiones.

En los dos libros de Ciencias consultados para este trabajo, más de la mitad de las veces se contaron figuras masculinas. De hecho, en uno de los textos (Serie hacia el Siglo XXI) las figuras masculinas se veían manipulando telescopios, microscopios y objetos que se emplean para realizar experimentos, en tanto que las figuras femeninas se mecen en una hamaca para ilustrar el movimiento o realizan tareas donde no es necesario el manejo de herramientas científicas. 
Por su parte, al revisar varios de los textos que actualmente se emplean en las clases de idioma extranjero en liceos públicos de Costa Rica, se sigue observando una predominancia de prejuicios e ideas conservadoras en cuanto a la división del trabajo. Para el tema de las profesiones o actividades cotidianas, se sigue ilustrando con mayor frecuencia a mujeres que laboran como dependientas, maestras, domésticas, enfermeras y secretarias; en tanto que la cantidad de hombres que fungen como ejecutivos, policías, bomberos, mecánicos y agricultores, es mucho mayor. Sin embargo, poco a poco se observa una evolución en estos patrones, y junto con los repetidos estereotipos laborales, algunos textos incluyen, al menos, una imagen en que aparecen hombres que cocinan y limpian, y mujeres que trabajan como programadoras de computación.

\section{En el enfoque dado a los textos literarios}

Mucho del tratamiento que se les da a los textos literarios que aparecen como material de estudio obligatorio cae en una posición poco progresista sobre las concepciones relativas a la mujer y al hombre.

Para nadie es un secreto que la literatura universal ha servido en buena medida como promotora de costumbres, ideologías y concepciones. Por ello, es lógico que durante siglos, los textos literarios más reconocidos llevaran una fuerte carga sexista, que de una u otra manera, buscaba manipular mediante la introducción de sutiles mensajes.

Lo terrible de esta realidad es que hoy, cuando estos textos son leídos y analizados por nuestras(os) adolescentes, se vean desde una óptica restringida y normativa, en que se destacan figuras literarias, tipos de narrador y espacios físicos o religiosos, pero se deja de lado la riqueza reflexiva que puede llevar a analizar a profundidad los textos literarios, y compararlos con otro tipo de discursos.

A manera de ilustración, puede señalarse el cuento "El Hijo", del uruguayo Horacio Quiroga. Esta narración forma parte de los programas de estudio de octavo año como ejemplo del posmodernismo. El cuento relata la angustia de un padre que ha salido de cacería y pierde de vista a su hijo por algunos minutos; al escuchar una detonación, el hombre presiente que el niño ha sufrido algún accidente, y comienza a buscarlo con una corazonada de muerte. En cierta parte del cuento, se lee lo siguiente: “-jChiquito!- se le escapa de pronto. Y si la voz de un hombre de carácter es capaz de llorar, tapémonos de misericordia los oídos...".

A pesar de la carga negativa que este fragmento reporta en relación con conductas socialmente aceptadas para mujeres y hombres, ninguno de los textos 
(Santillana, Textos de Lectura y Comentarios), que se publican como auxiliares para el análisis literario, menciona el asunto ni destaca en absoluto la temática sexista del cuento. Tras un breve sondeo con profesores de Español (3 docentes en total) que han debido facilitar clases referidas a este cuento, ninguno dijo haber destacado el fragmento durante el análisis, ya fuera porque lo pasaron inadvertido o porque se sujetan estrictamente a lo mencionado en las guías.

Como esta, otras obras son leídas y asumidas por las y los jóvenes de escuelas y colegios, sin que exista un adecuado procesamiento y discusión de los mensajes que transmiten; esto contribuye a la perpetuación de estereotipos y desigualdades.

\section{En las evidencias de aula}

Es innegable que la socialización produce conductas distintas entre mujeres y varones, lo cual se verificó al comparar trabajos realizados por estudiantes femeninas y masculinos de colegio y universidad.

En grupos de sétimo año, tras realizar la lectura y análisis del cuento "El Gato Negro", se les pidió a las y los jóvenes que escribieran o dibujaran pancartas en que protestaran contra alguno de los temas que se desarrollan en el cuento. En más de un $80 \%$ de los casos, los niños hicieron pancartas que se basaban en el dibujo o grafiti, matizadas apenas por alguna palabra; en cambio, las niñas produjeron mucha más escritura y color, y se centraron en dar mensajes expresados por la palabra.

Por su parte, estudiantes de segundo año de la carrera de Educación Rural de la UNA, que debían elaborar un álbum de materiales, mostraron también enormes diferencias en la presentación de sus trabajos, hablando comparativamente de mujeres y hombres. Las estudiantes decoraban mucho más las portadas de sus álbumes, y solían incluir colores pastel entre los materiales. Los hombres, en cambio, se limitaron a ofrecer sus propuestas por escrito, y por lo general, cuando incluían materiales, eran dibujos o ilustraciones sin colores.

En cuanto a la participación en debates, tras escuchar las grabaciones de dos grupos de estudiantes de noveno año, y una de un grupo de universitarias(os), quedó claro que las intervenciones de las mujeres eran mucho más frecuentes y vehementes; por lo general, incluían relatos de experiencias personales que servían para sustentar la opinión o comentario que estaban dando. Los varones, por su parte, intervenían menos y no daban narraciones de experiencias, pero sí hacían comentarios que, en promedio, duraban un tercio más que cada incursión femenina. No obstante, al comparar el total de tiempo que cada grupo habló, la cantidad de minutos era similar, y el número de mujeres que 
manifestaron su opinión públicamente era mucho mayor que el de varones, sobre todo entre las colegialas.

En este sentido, se observa una ruptura en relación con lo dicho por Tannen (1993), quien, producto de observaciones y estudios, aseguraba que la mujer era mucho más discreta en el habla pública.

\section{Según lo manifestado por estudiantes y docentes}

Al preguntarles en forma directa a estudiantes y docentes si consideraban que la educación costarricense perpetuaba o no mitos, las respuestas fueron encontradas. Específicamente, las estudiantes de noveno año dijeron que las oportunidades para ellas eran menores, y que la educación no siempre estaba de su lado. Una de las muchachas dijo que eran obvias las diferencias, incluso en el trato que se les daba a las profesoras y los profesores de su colegio, señalando que para ellos había mayor consideración; pues, aunque desde su percepción, algunas docentes trabajan más en la planificación de lecciones y elaboración de materiales, se veía que las consideraciones por parte del Director de la institución eran para los profesores (dijeron que nunca habían escuchado al Director llamándole la atención a un profesor, pero que sí lo habían escuchado varias veces reprendiendo a las docentes; lo que para ellas, les restaba autoridad y mostraba machismo y falta de respeto profesional).

Por su parte, aunque las(os) educadoras(es) están tratando de incorporar los temas transversales a su práctica curricular, todavía hay cierta resistencia, ya que perciben esta pauta como una adición a su jornada laboral.

$\mathrm{Al}$ hablar con los varones sobre sus ideas en cuanto a la división del trabajo y las tareas tradicionalmente delegadas a hombres o mujeres, fue evidente y hasta muy franca la posición machista y tradicional: "un hombre no puede tener un secretario, todos los estilistas son 'gays', las mujeres manejan muy mal, las mujeres tienen más responsabilidad en cuanto a cuidar su apariencia, etc.". Cuando se les preguntó qué decían sus profesores respecto a estas opiniones, algunos dijeron que sabían que sus docentes pensaban igual, pues habían comentado cosas parecidas o habían participado de chistes sexistas.

También, se vio que, aunque la mayoría de los estudiantes cree que las mujeres tienen derecho a trabajar y desarrollarse profesionalmente, siguen pensando que en asuntos sexuales ellas deben cuidarse más y ser más "recatadas".

Los docentes consultados dijeron que en sus materias, por lo menos, no se hacía o decía nada que estimulara alguna conducta machista; aunque varios de ellos emplean libros de texto que focalizan la atención sobre modelos masculinos o participan de conversaciones, en que de alguna manera, se discrimina 
a la mujer. Ninguno de los profesores manifestó la incorporación del tema en sus lecciones, ni siquiera como punto focal de los temas transversales.

\section{Hallazgos}

- La educación costarricense sigue perpetuando mitos relativos a la diferenciación entre géneros, ya sea de manera explícita o implícita; lo anterior se verifica mediante los modelos transmitidos en los libros de texto de todos los niveles educativos.

- $\quad$ Aunque al comparar los textos que se emplean en la actualidad con los que se utilizaban hace diez o doce años, se ve un manifiesto progreso en la división de roles y la concepción tradicional de la mujer y el varón, todavía falta mucho camino que andar y muchas concepciones que deben cambiarse.

- La literatura obligatoria suele enfocarse de manera tal que, lejos de promover la crítica reflexiva y la apertura de mentalidades, fortalece los modelos tradicionales como fuente de prejuicios negativos, dado que no se le da un adecuado tratamiento ni se enfatiza en análisis apropiados y profundos.

- Las y los docentes no se preocupan lo suficiente por analizar sus conductas, comentarios o actividades, y suelen caer en la repetición de patrones que marcan las diferencias de género.

- Las jóvenes de secundaria sienten y se percatan de actitudes y comentarios que las colocan, de alguna manera, en desventaja social, lo que las impulsa a estar más alerta y a buscarse un espacio en las intervenciones públicas.

- $\quad$ Es indiscutible que, producto de la socialización, mujeres y varones concebimos el mundo desde perspectivas un tanto distintas, por lo que los trabajos y las producciones que ejecutemos, estarán permeados por ese influjo.

\section{Recomendaciones}

Es necesario que quienes laboran como educadoras(es), estén alertas ante cualquier tipo de mensaje sexista que pueda generar discriminación. No sólo se debe tener cuidado en cuanto a conductas particulares, sino en relación con el tratamiento que se le dé al material didáctico y los libros de textos que cada docente emplee, y a la forma en que se oriente la discusión sobre estos hechos.

También, vale la pena que las y los docentes vuelquen la mirada hacia los temas transversales que para este año el Ministerio de Educación Pública 
introdujo en los programas de todas las materias y niveles: gran parte de esas competencias van orientadas hacia el respeto, la tolerancia, la no discriminación y el sentido de equidad en las relaciones interpersonales, especialmente con el otro género.

Por último, es necesario que el Ministerio de Educación Pública oriente la forma en que docentes y estudiantes perciben la división de géneros y las conductas sexistas. Es importante realizar investigaciones que definan este panorama, y ofrecer constante apoyo y capacitación en cuanto a la manera en que los temas transversales deben impactar la totalidad de las prácticas pedagógicas, y cómo estas pueden focalizar asuntos de equidad en todas las áreas y disciplinas. 


\section{Referencias}

Alvarado, Rosalinette y otros (2003) Mundo Ciencia. San José: Eduvisión.

"Balance sobre la equidad de género en la Universidad de Costa Rica". Disponible en www.ucr.ac.cr. 2005.

Barrios, Rosa y Gutiérrez, Ivannia (1990) Modelos de Género y Sexismo en los Libros Escolares de Primaria. Managua: UNIFEM.

Beauvoir, de Simone (1987) El Segundo Sexo. Buenos Aires: Ediciones Siglo XX. Bermardini, A. (1985) La Educación Actual en sus Fuentes Filosóficas. San José: EUNED.

Bernstein, B. (1975) La Estructrura del Discurso Pedagógico. Madrid: Morata. Calvo, Yadira (1984) Literatura, Mujer y Sexismo. San José: Editorial Costa Rica.

Calvo, Yadira (1990) La Mujer por la Palabra. Heredia: Editorial Universidad Nacional.

Ciencias 8 Serie Hacia el Siglo XXI (1998) San José: Editorial Costa Rica.

Durán, J. (1983) La Perspectiva Conservadora. Año 1. Volumen 1. Pp. 30-48. Argentina: Feminaria Editora.

Flores Ochoa, Raquel (1994) Hacia una Pedagogía del Conocimiento. Bogotá: McGraw Hill Interamericana, S.A.

Freire, Paulo (1996) Pedagogía de la Autonomía. Madrid: Siglo Veintiuno Editores, S.A.

Freud, S. (1967) Obras Completas. España: Espasa-Calpe.

Gallon, Fabienne (2002) Extra 1. Madrid: Ediciones SM.

González, Mirta (2000) El Sexismo en la Educación. San José: Editorial de la Universidad de Costa Rica.

Hernández, Gloria (2001) Tobogán 1. San José: Grupo Editorial Norma.

Lozano, Irene (1998) Lenguaje Femenino, Lenguaje Masculino. Madrid: Editorial Minerva.

Marx, K. (1970) Contribución a la Crítica de Economía Política. Madrid: Corazón Editor.

Monge, Raquel y otros (2002) Leer y Pensar 8. San José: Editorial Santillana.

Mora, Laura y otras (2001) "La imagen corporal en adolescentes: expresión de los aprendizajes socioculturales adquiridos sobre el ser mujer". Educación. San José: Editorial de la Universidad de Costa Rica.

Moreno, M. (2003) “Lenguaje y sexismo”. Cómo se enseña a ser niña: el sexismo en la escuela. Alicante: Feminario.

Ortega, Félix y otros (1989) “Objeto y perspectivas teóricas”. Manual de Sociología de la Educación. Madrid: VISOR.

Palomar, Cristina (2003) “Los estudios de género y la educación”. La Ventana. México: Universidad de Guadalajara.

Tannen, Deborah (1993) Tú no me Entiendes. Buenos Aires: Javier Vergara Ediciones. Textos de Lectura y Comentarios 8 (2002) San José: Editorial Femández Arce.

Traducción del Nuevo Mundo de las Santas Escrituras (1987) Brooklyn: Watchtower Bible and Tract Society. 